\section{Identidades: construcción y cambio}

Manuel Carballo *

\begin{abstract}
Resumen: Las identidades culturales no deben leerse como esencias a ser recuperadas de una mixtura que corroe su pureza. Si algo caracteriza las identidades es el cambio. Recuperando la dimensión de lo identitario como construcción colectiva y ficcional, es posible rescatar también su condición estratégica en la trama simbólica de las diferencias.
\end{abstract}

Palabras clave: cambio - construcción - diferencia - identidades culturales - ficción.

[Resúmenes en inglés y portugués en la página 24]

${ }^{(*)}$ Licenciado en Comunicación Social y se encuentra cursando estudios de posgrado en Ciencias Sociales en la UBA. Es docente en la Universidad de Palermo y en otras universidades. Trabaja como Periodista para distintos medios gráficos.

La identidad no existe. Está bien, no es la mejor forma de empezar un breve ensayo sobre el tema, negándolo, pero es necesario dejar en claro antes de lo que no se trata. Muchas argumentaciones acerca de la identidad la confunden con un reservorio claramente visible de características, cuya historia puede buscarse en una raíz tan profunda que es prácticamente lo mismo decir que han existido toda la vida. Es más, muchos de estos atributos son percibidos frecuentemente como esenciales, sin los cuales un objeto o sujeto se desdibujaría como tal. La identidad es así entendida desde el rígido molde del esencialismo como un dogma compacto que se debe restaurar frente a cualquier amenaza que intente degradarlo o pervertirlo. La identidad aparece como la garantía de lo auténtico, asemejada a lo verdadero y asociada con la posibilidad de conservar un núcleo seminal que no debe tergiversar ni negociar su pureza. El tiempo parece quedar suspendido en ese concepto de lo identitario, o mejor, parece retomarse incansablemente en el mismo fragmento eternizado.

Por el contario, podemos decir entonces, que cuando hablamos de identidad no nos estamos refiriendo a un fenómeno homeostático sino a una configuración que fondea su significado en el cambio. No es una esencia sino todo lo contrario, una construcción colectiva permanente.

Si tuviésemos que realizar un listado de los caracteres de determinada situación identitaria, por ejemplo, los que implican la pertenencia a un país, podríamos comenzar enumerando ciertas particularidades por las que son reconocidos sus integrantes: su lengua, los deportes más populares, sus comidas típicas, sus formas de vestir, sus códigos de convi- 
vencia, su música, sus bailes, sus triunfos en la ciencia y el arte, sus capacidades productivas, etc. Si repasamos esa supuesta lista, podríamos compararla con la que se hubiese confeccionado años antes, diez, veinte, cien, para ver cómo la dimensión temporal desbarata la sustancia esencial. No obstante, seguramente habrá algún habitante actual que sienta pertenecer a ese país y no guste de su música o comidas típicas, o ignore los éxitos del arte y la ciencia, o incluso no hable muy bien su lengua. Es allí donde las correspondencias de lo identitario y la pertenencia a ese colectivo tienen un vínculo difuso. Seguramente, diez personas confeccionando estos ítems aquí y ahora, tarden en acordar exactamente cuáles son en los que coinciden plenamente.

\section{No es la tradición}

Es en la idea de tradición donde confluyen las visiones esencialistas de la historia y de las identidades. Estamos de acuerdo en que la identidad no se conforma en el vacío, un varón con identidad de género masculina, no inventa de la nada qué es ser hombre, qué se considera que transgrede esa definición, y qué debe hacer para mostrarse como tal. En algún momento aprende que la sociedad de la que es producto y productor espera ciertas formas de comportamiento relacionadas a la identidad de lo masculino, y si él se reconoce como tal, deberá afrontarlas. Claramente sabrá que usar capelina, o vestido no corresponden con esa condición identitaria. Su identidad no sobrevendrá de la nada, sino que tendrá en cuenta la tradición que reproduce lo masculino con características distintivas en una cultura y un momento determinados. A la vez, la conformación de su identidad de género tendrá que ver con la actualización de esa tradición, la puesta en tiempo histórico propio de esas costumbres que indican qué y cómo vestir. Es así como la falda, característica inobjetable del vestir femenino es explorada de tanto en tanto por grupos de varones tensionando las fronteras de lo que la tradición establece que debería ser. Algo similar sucedió con el uso del pantalón por parte de la mujer durante el siglo XX. Una prenda de tradición masculina, fue parte de la revolución del prêt-à-porter y también comenzó a formar parte del guardarropa femenino.

La identidad tiene como insumo fundamental a la tradición, pero no es su duplicación exacta, sino que siempre se tratará de una adaptación, y una actualización que la llevarán a constituirse en algo nuevo y diferente. Es así como los discursos que confunden una con otra, borran toda construcción posterior en base a esa tradición. Todo lo que no es asimilable con el contenido original es incluso muchas veces combatido, porque supone que hay allí una seducción maligna y perniciosa que busca torcer ese corazón intacto y valiosísimo que es la tradición.

Creo evidente que no toda tradición, por más antigua que sea, se legitima como práctica social en la actualidad. Los ejemplos sobreabundan. La esclavitud, el trabajo infantil, el menosprecio de la mujer, por comentar algunos, fueron en su momento prácticas tradicionales. De la misma manera, se puede leer en clave de tradición, el sentido extractivo de explotación de los recursos naturales que se ha llevado adelante desde la Revolución Industrial y que ha permeado culturalmente cómo sus habitantes conciben el entorno.

También abundan los ejemplos que muestran a las prácticas sedimentadas históricamente 
como una experiencia imborrable e ineludible, como una resolución original fruto de siglos de mejoramiento sistémico de metodologías ensayadas a lo largo de diferentes contextos sociales, económicos o ecológicos. Pero hay que aceptar el hecho de que la tradición se desfase y que siempre necesite para concretarse de una actualización de sus valores y premisas.

\section{Igual a sí mismo}

Existe un principio básico de la lógica que indica que toda entidad es igual a sí misma, y como bien explicitó Wittgenstein para que esto sea así, debe existir algo que sea diferente. Para que A sea A, debe existir algo que se le oponga como no-A, como algo distinto a A. Lo mismo sucede con las identidades en el campo de la cultura. Para que existan identidades definidas, deben existir otras con las cuales compararlas y encontrar diferencias. Si no existieran características culturales que diferenciaran al género masculino de lo femenino, no habría necesidad de designarlos mediante significantes diferentes. Si todos perteneciéramos al mismo país no existiría el concepto de extranjería. Lo mismo sucede con cualquier definición, cuadros de fútbol, partidos políticos, géneros musicales. Algo comienza a ser, a constituirse como tal, cuando hay particularidades que lo muestran noigual a otra cosa. La posibilidad de distinción y de diferenciación se haya en el centro de la conformación de la identidad. La tradición es la lista de esas particularidades-diferencias que pueden remontarse históricamente para ubicar el objeto en un punto determinado de la trama simbólica.

Está en la identidad del juego del seleccionado de fútbol brasileño, el buen trato del balón, el juego armonioso que hace emerger al futbolista como inspirado creador, ilusionista y malabarista, más que como atleta denodado. Esa identidad fue fijada en una tradición que se sedimentó entre los años cincuenta y setenta a la luz de sus éxitos deportivos. Cuando la gramática del juego brasileño quiere actualizar su tradición a los cánones de entrega física extrema de los futbolistas en el campo de juego, es criticada su visión del deporte que se distancia de su herencia inmediata. Qué diferencia entonces al fútbol brasileño del uruguayo o del argentino. Si no hay posibilidad de distinguir las fronteras y los cambios de estas conformaciones identitarias, hay algo que se pierde, hay algo que queda subsumido en otra cosa, se vivencia la tradición traicionada, la historia dilapidada, la amalgama confusa en el todo indiscernible del juego sudamericano.

Se necesitan los bordes, el trazar límites que impliquen las formas arbitrarias de las cosas. Saber dónde comienza y termina algo, implica la posibilidad de tener una cartografía clara y precisa que permite una forma más estacionaria y aprehensible de lo simbólico. Esto es lo que el mundo contemporáneo ha trastocado de manera violenta haciendo emerger tantas discusiones en torno de la modificación de esas formas históricas que se mostraban con dinámicas tan lentas que parecían no moverse.

A partir del siglo XVI, una discusión atenta contra el resquebrajamiento del discurso religioso en general. ¿El nombre de la cosa es algo que la cosa porta, que se ha fundado más allá de cualquier intervención del hombre?; ¿el nombre de la cosa es la marca de ese sujeto divino que se designa como Dios, o es obra de ese sujeto mundano que hemos llamado hombre? Esta discusión que para la lingüística saldará Saussure recién a comienzos del 
siglo XX es parecida a la que se da actualmente sobre las identidades. La respuesta del fundador de la lingüística se basaría en la arbitrariedad del signo lingüístico. Podríamos hablar actualmente de la necesidad de concebir a las identidades también de la misma manera.

\section{Una ficción necesaria}

Cuando Saussure define al signo como arbitrario no está diciendo que éste sea por esa causa, falso, dañino, ni siquiera alejado de su condición de portar significados religiosos. De la misma manera, cuando se define a las identidades como ficcionales tampoco se evalúa o se enuncia su falsedad o inverosimilitud. Las identidades son ficciones que una comunidad se brinda para sí, en base a una historia-tradición común que actualizará en el tiempo. Estas ficciones se constituyen a través de discursos, en forma de relatos, máximas, juicios de valor, mitos, fábulas, noticias periodísticas, cantos de guerra, etc. Cada vez que establezca un "nosotros", es decir inscriba en un discurso ese yo plural (me incluya a mí o no) estaré dando una puntada más en el tejido ficcional de lo identitario. Cuando digo "los argentinos", y les asigno algún atributo, se entiende que es un colectivo del que solamente nos permitimos pensar algo de las características particulares de esas individualidades contenidas por el grupo. Si achicamos el colectivo, y en vez de hablar de argentinos decimos, los intelectuales argentinos, sucede exactamente lo mismo. ¿Qué atributo puede ser correcto para asignársele a una cantidad de seres humanos que habitan tantas realidades distintas dentro de un territorio? Por más generalizada que sea esta cualidad nunca alcanzaría a la totalidad de personas que integran ese grupo. Lo mismo puede hacerse con grupos más chicos como un equipo de fútbol, los socios de una biblioteca, los integrantes de un curso universitario, los que beben en la barra de un bar. Incluso la identidad de la persona como unidad mínima e indivisible es cuestionada.

El desarrollo de técnicas para el registro y almacenamiento analógico de la imagen y el sonido en el siglo XIX permitieron constituir una base de datos extensa acerca de las formas del escuchar y el ver, y completar el archivo que se había iniciado con los documentos escritos. Esa colección que se ha sofisticado con el registro y almacenamiento digital y viralizado a través de las redes de circulación de información, resiste una comparación de algunas de sus formas concretizadas a lo largo de la historia. Para Ricoeur (1996) la incapacidad de mantener la totalidad de nuestras opiniones a lo largo del tiempo de nuestra vida es prueba de esto, comprobable a través de cualquier seguimiento de las noticias de un diario o del registro audiovisual de nuestras vacaciones. No existe eso que llamamos identidad personal tampoco, o sólo existe en una dimensión temporal acotada. Es una ficción que creamos para nosotros mismos que existimos como sujetos que pertenecen a una tradición que deben respetar, o que son irreverentes, o afables o inteligentes o superficiales. Por supuesto, todo esto basado en tradiciones que se manifiestan desde antes que nazcamos en nuestro núcleo familiar, se componga como se componga. Sobre este tipo de discursos que nos ficcionaliza y nos transforma en sujetos es que operará la técnica del psicoanálisis, tratando de hacer evidentes esas relaciones entre historia y la asunción de roles y discursos que se nos han impuesto. 


\section{No se gana ni se pierde}

Para Stuart Hall (2003) no es posible perder ni ganar las identidades. Es posible hacer los trámites correspondientes frente a la burocracia de un Estado para que me consideren ciudadano de un país determinado. Pero eso no implica que esa acreditación de orden legal, un documento, me asigne automáticamente una identidad. Tampoco garantiza la identidad que tome como propios ciertos dispositivos simbólicos: costumbres, jergas lingüísticas o modos de observar la ley. Si bien hay un aparato jurídico que asigna pertenencias, no lo hay para las identidades. No hay un tribunal frente al cual pueda acreditar que soy hincha de fútbol, que me gusta la cumbia o la danza contemporánea. Hay algo en la identidad que tiene que ver con el lugar que se da a sí mismo el sujeto en ese mapa de diferencias y eso es intrínsecamente personal, ligado a lo sentimental, pero también a una práctica, a un hacer, a un constituirse en eso que se vivencia que se es.

Lo mismo ocurre con la pérdida. Después de estar alejado por cualquier motivo del lugar de origen, nuestra identidad puede seguir estando ligada a ese espacio simbólico aunque no exactamente se lo habite físicamente. Aun cuando deje de ir a ver mi equipo de fútbol al estadio o a los recitales de mi banda preferida, el lazo identitario puede mantenerse intacto. De la misma manera, por ejemplo: ¿quién puede establecer que alguien no es hombre porque llora mirando una película romántica?

Nadie puede enunciar que resume sobre sí la identidad de lo porteño, o que tal o cual forma expresiva sintetiza la identidad de las vanguardias. No hay quién pueda arrogarse esa potestad, o pongámoslo de otro modo, si alguien lo hace solamente está enunciando uno de los discursos posibles acerca de lo identitario, que nunca se subsume en lo uno.

Para Hall (2003) las identidades se construyen a partir de los discursos. Son los discursos en torno a la identidad los que amalgaman individuos ganando su adhesión para sí. No es en otro lado donde se juegue la identidad, sino en los discursos que se producen sobre ella, los que ella promueve y permite a su vez que se produzcan y propaguen. En los estadios de fútbol, las simpatizantes producen los discursos que los separan de su diferente y los legitiman dentro del marco identitario en el que se reconocen. De esa manera enuncian, casi siempre en forma de cántico o impreso en algún soporte que asemeja una bandera, que el rival, el otro, es cobarde, renuente a la batalla o que se ampara en las formas instituidas por la ley. Cuando esos mismos estadios son la escena en el que las bandas de rock construyen sus propios dispositivos, los fans establecen consignas que los diferencian de otras bandas u otras maneras de configurar el ritual del rock. Eso no es tácito o se da por medio de la telepatía, o una sensación un tanto mística de sentir la energía del ambiente. Los discursos son formas de materialización bien concreta de la arbitrariedad en la que la trama simbólica se diagrama y se divide.

La pertenencia a los grupos denominados tribus urbanas (Maffesoli, 2009), puede ser otro ejemplo para abordar esta situación. Pertenezco a los emos, o darks, cuando comienzo a producir discursos en los que me ubico como yo, dentro de sus enunciados. "Nosotros los emos, somos de tal manera", o "a diferencia de los emos, los darks somos...". Esa ficción que supone ser de tal o cual tribu urbana, se sostiene en la fuerza simbólica tejida por esos discursos que establecen y dejan para que la historia los sedimente en tradición, las bases constitutivas de la pertenencia. Ahora, la pertenencia a un grupo identitario cualquiera, como bien reconoce Hall (2003), no cancela la diferencia al interior del grupo. Justamente esa es la ficción de la cual la identidad se nutre y por la que sobrevive como tal. Cuando 
pensamos que un colectivo tan vasto como los integrantes de un partido político puede quedar subsumida a consignas de la primera mitad del siglo XX, o a los lineamientos de una campaña por cargos electivos, nos damos cuenta que allí no hay más que creencias de base ficcional. Cada colectivo recubre de manera diferente esa ficción, los refuerza con ideas como lealtad, patriotismo, sentir popular, y constituye verosímiles en los que deja afuera y adentro a sus integrantes. Es mediante el relato o la sutura discursiva (Hall, 2003) que estos enunciados se revelan como dispositivos capaces de coordinar fuerzas, de otorgarle una dimensión física al poder, de habilitar o reprimir espacios de saber.

La política siempre tuvo muy en claro, incluso antes de los estudios de comunicación, de Foucault o del marketing político, que las identidades se juegan en esta producción simbólica discursiva. El conflicto entre medios de comunicación y muchos de los Gobiernos de los Estados actualmente, más allá de las particularidades en que cada discusión se desarrolla, implica el haber hecho evidente esta relación y competir abiertamente por la producción de discursos.

\section{Estados nación y su crisis}

El Estado nación se maceró en las conquistas internas del territorio y en conflictos sobre fronteras durante todo el siglo XIX y consolidó sus atributos en el comienzo del XX. Uno de los dispositivos con los que afianzó la pertenencia territorial fue la escuela. Es obvio que el lenguaje es uno de los primeros dispositivos de subjetivización (Agamben, 2005) que han desarrollado los seres humanos y por medio de la institución educativa éste podía diseminarse en toda la extensión geográfica. Estos Estados funcionaron como identidades más o menos compartimentadas logrando adhesiones irregulares a lo largo de su historia. A partir de sus crisis, étnicas, religiosas, culturales y políticas, los Estados han disminuido considerablemente su poder para establecer dispositivos que aten a los sujetos a su territorio. Entre otras cosas, las novelas románticas, el periodismo, los viajes en barco y luego en avión, y los dispositivos ligados a las tecnologías de la información y la comunicación masiva contemporáneos han horadado su efectividad de manera considerable.

Los medios de comunicación incluso, a partir de los años 80 en América Latina, se han convertido en instituciones frente a las cuales peticionar remplazando las clásicas propuestas por el Estado: partidos políticos y sindicatos. El mercado ha aparecido como el lugar en el que participar mediante el acto de consumir, substituyendo las discusiones sobre lo público e incluso el mismo interés en el derecho de elegir representantes. La política no ha gozado de una valoración positiva durante la última década del XX, para repensarse en procesos complejos a partir del 2000. Las identidades colectivas han sufrido la crisis de los dispositivos que las venían constituyendo a partir de la modernidad y el consumo y el espectáculo han emergido como modeladores privilegiados.

Algunos Estados, claramente han desarrollado nodos (Appadurai, 2004) en los que confluyen los capitales que desarrollan industrias en relación al entrenamiento basados en el consumo y el espectáculo. De esa manera se han colocado en una posición comparativamente favorecida frente a lo simbólico y a la capacidad de conformar subjetividades. Hay que tener en cuenta, igualmente, como sugieren los autores de la Escuela de Birmingham o antropólogos como García Canclini (1995) que la actividad de consumir no ubica al suje- 
to como víctima de un mercado que le impone objetos, sino como alguien que decide, elige, se apropia y reconfigura sus ofertas. Igualmente ese mercado para optimizar recursos tiende a homogeneizar sus productos y por lo tanto ofrecer con ciertas particularidades las mismas cosas en todos lados. Es así como en los barrios de comercios populares de Buenos Aires, Barcelona, Bogotá o el D.F., encontraremos productos similares o exactamente iguales. Por lo cual la pluralidad del mercado sobre el que los consumidores eligen es de una escasez cada vez más concentrada.

Frente a esta situación las alternativas para producir objetos, y en general para concebir dispositivos de construcción de subjetividades, más conectados con el sujeto consumidor han comenzado a pensar lo local como punto de partida. Si bien las oposiciones entre lo local y lo global se han mostrado muchas veces falaces, improcedentes, y han develado anacronías productivas tanto como el dilapidamiento de recursos humanos y naturales, la hegemonía de lo global es tan asfixiante que en muchos casos se transforma en un obstáculo cuando no en una amenaza seria a la existencia. Incluso la cooperación entre las nuevas formas de comercio en la economía globalizada y la producción local y simbólicamente resistente a la heterogeneidad también han tenido sus objeciones. Ya que si bien son transacciones que funcionan habilitando nuevos puntos de venta y colocación de las economías regionales, las condiciones de explotación que supone algunas veces los intercambios de productos son pasmosas. La panacea del comercio internacional ha arrinconado la fuerza de trabajo y la ha obligado a "flexibilizarse" hasta límites que retrotraen las condiciones laborales a los comienzos de la Revolución Industrial. Los empleados de Apple en China, no son remunerados siquiera para que puedan comprar los productos que ellos mismos ensamblan y son obligados a firmar contratos absurdos que incluyen que no van a suicidarse mientras estén empleados. El trabajo esclavo es una constante y no solamente en América Latina o Asia, sino también en Europa y en Estados Unidos. Así y todo, frente a la necesidad de lograr economías de subsistencia, las particularidades de lo local se muestran como un valor agregado frente a la tendencia homogeinizadora de las lógicas productivas.

\section{Las identidades ligadas a lo estratégico}

Si bien las identidades son ficciones contingentes, funcionan como posiciones estratégicas en la red simbólica que otorgan ventajas competitivas. Muchos colectivos han recurrido a su historia cultural para reapropiarse de sus tradiciones no solo como una forma de resistencia simbólica, sino como una manera de reconectarse a su entorno natural, a su estructura de vínculos filiales y en general a los dispositivos que durante mucho tiempo garantizaron la supervivencia de sus comunidades. En este sentido la revaloración de las identidades locales no constituyen un brote esquizofrénico, ni etnicista, sino implican una intención de establecer una apuesta estratégica frente a los espacios de producción industrial que fueron ocupados desde la expansión de los mercados después de la primera mitad del siglo XX. Si lo único que se tiene es la fuerza de trabajo y el mercado la maltrata y mal remunera, un giro interesante es la gestión de nuevos modelos productivos en donde el aporte implique algo diferente que la mera participación como insumo básico intercambiable.

Para América Latina la constitución de las burguesías locales fue un difícil camino, en muchos casos frustrado, cuyos resultados están siendo revaluados luego de las privatizaciones de 
las últimas décadas del siglo XX. Frente a la estandarización de los modelos productivos que no pudieron consolidar en muchos casos empresarios nacionales fuertes y con capacidad de emplear mano de obra, las dinámicas regionales de producción brindan al menos la sensación de que existen formas alternativas de crear valor y de concebirse como trabajadores. La conformación de redes identitarias se asienta entonces en esta necesidad que expresa el contexto productivo. Establecer ese entramado, supone reconocer antes la madeja de la cual se servirán los actores que comiencen a elaborar los discursos necesarios. Solamente hay diseñadores con improntas locales si se producen discursos que expresen puntos de vista sobre las particularidades de tal configuración.

La identidad será así entendida no solamente como una construcción que habilita una forma alternativa de producción y comercialización sino como la revalorización de lo propio en el intercambio permanente de las diferencias.

No es volver a las raíces, eso es imposible. Las raíces están enterradas bien profundo y el camino hacia ellas lo único que lograría es soterrar a quien viva en la ilusión de encontrarlas. El desafío es recorrer la contemporaneidad recurriendo a pensarnos y transformarnos como sujetos con todas las herramientas posibles: los modelos históricos de la tradición actualizada y también los del otro, del diferente, cuyos esquemas nos resultan a veces seductores o nos repelen hasta la intolerancia.

\section{Referencias Bibliográficas}

Agamben, G. (2005). ¿Qué es un dispositivo? Conferencia en la Universidad Nacional de La Plata, Buenos Aires.

Appadurai, A. (2004). La modernidad desbordada. Dimensiones culturales de la globalización. Barcelona: Fondo de Cultura Económica.

García Canclini, N. (1995). Consumidores y ciudadanos. México: Grijalbo.

Hall, S. (2003). Cuestiones de identidad cultural. Madrid: Amorrortu.

Maffesoli, M. (2009). El tiempo de las tribus. México: Siglo XXI editores.

Ricœur, P. (1996). Sí mismo como otro. México: Siglo XXI.

Summary: Cultural identities should not be read as essences to be recovered from a mixture that corrodes its purity. If anything characterizes the identity is change. Retrieving the dimension of collective identity as a fictional construction, you may also redeem their strategic status in the symbolic pattern of differences.

Keywords: change - construction - cultural identities - difference - fiction.

Resumo: As identidades culturais não devem ler-se como essências a serem recuperadas de uma mistura que desgasta sua pureza. Se alguma coisa caracteriza as identidades é o câmbio. Recuperando a dimensão do identitário como construção coletiva e ficcional, é possível resgatar também sua condição estratégica na trama simbólica das diferenças.

Palavras chave: câmbio - construção - diferença - ficção - identidades culturais. 